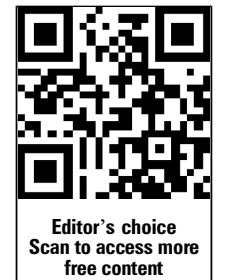

- Additional material is published online only. To view please visit the journal online (http://dx.doi.org/10.1136/ bjsports-2013-092886).

For numbered affiliations see end of article.

\section{Correspondence to} Elena Pocecco,

Department of Sport Science, Medical Section, University of Innsbruck, Fürstenweg 185 , 6020 Innsbruck, Austria; elenapocecco@yahoo.it

Accepted 13 October 2013

To cite: Pocecco $\mathrm{E}$,

Ruedl G, Stankovic N, et al.

Br J Sports Med

2013;47:1139-1143.

\title{
Injuries in judo: a systematic literature review including suggestions for prevention
}

\author{
Elena Pocecco, ${ }^{1}$ Gerhard Ruedl, ${ }^{1}$ Nemanja Stankovic, ${ }^{2}$ Stanislaw Sterkowicz, ${ }^{3}$ \\ Fabricio Boscolo Del Vecchio, ${ }_{1}^{4,5}$ Carlos Gutiérrez-García, ${ }^{6}$ Romain Rousseau, ${ }^{7,8}$ \\ Mirjam Wolf, ${ }^{1}$ Martin Kopp, ${ }^{1}$ Bianca Miarka, ${ }^{5}$ Verena Menz, ${ }^{1}$ Philipp Krüsmann, \\ Michel Calmet, ${ }^{9}$ Nikolaos Malliaropoulos, ${ }^{10,11}$ Martin Burtscher ${ }^{1}$
}

\section{ABSTRACT \\ Background There is limited knowledge on epidemiological injury data in judo.}

Objective To systematically review scientific literature on the frequency and characteristics of injuries in judo. Methods The available literature up to June 2013 was searched for prospective as well as retrospective studies on injuries in judo. Data extraction and presentation focused on the incidence rate, injury risk, types, location and causes of injuries.

Results During the Olympic Games in 2008 and 2012, an average injury risk of about $11-12 \%$ has been observed. Sprains, strains and contusions, usually of the knee, shoulder and fingers, were the most frequently reported injuries, whereas being thrown was the most common injury mechanism. Severe injuries were quite rare and usually affected the brain and spine, whereas chronic injuries typically affected the finger joints, lower back and ears. The most common types of injuries in young judo athletes were contusions/abrasions, fractures and sprains/strains. Sex-differences data on judo injuries were mostly inconsistent. Some studies suggested a relationship between nutrition, hydration and/or weight cycling and judo injuries. Also, psychological factors may increase the risk of judo injuries.

Conclusions The present review provides the latest knowledge on the frequency and characteristics of injuries in judo. Comprehensive knowledge about the risk of injury during sport activity and related risk factors represents an essential basis to develop effective strategies for injury prevention. Thus, the introduction of an ongoing injury surveillance system in judo is of utmost importance.

\section{INTRODUCTION}

Judo is a martial art and an Olympic sport comprising standing and ground fighting. ${ }^{1} 2$ It entered the Olympic Programme for men in 1964 as a demonstration sport and officially in 1972 for men and in 1992 for women. ${ }^{3}$ During competitions, contestants are divided by sex, sometimes by grade or judo experience, and organised in age classes and weight divisions. ${ }^{4}$

Nowadays, judo ranks among the most popular Asian martial arts in the world. ${ }^{5}$ The International Judo Federation comprises more than 200 affiliated countries spread over all five continents, counting an estimated 20 million individuals. ${ }^{6}$ Considering such a high participation rate in a combat sport and the suggested relatively high injury risk, ${ }^{7}$ the safety of practitioners is of the highest priority. Therefore, research on judo injuries would be essential in identifying risk factors and suggesting potentially preventive strategies.

To protect the health of its athletes, the International Olympic Committee initiated and developed the injury and illness surveillance system during the 2008 Beijing and 2012 London Olympics. ${ }^{89}$ With this systematic injury registration, the most common and severe injuries, for example, in judo athletes, are identified to ensure new knowledge on injury trends over time, to form the basis for further research on injury risk factors and mechanisms, and finally to develop injury prevention programmes. ${ }^{10}$ However, the collection of epidemiological data is just the first step in the direction of injury prevention, which should be followed by more deepening studies on judo peculiarities.

In the literature, a few prospective and retrospective studies as well as case reports dealing with judo injuries are available. ${ }^{11-13}$ However, to our knowledge, no systematic overview on this important topic is available. Therefore, the aim of this paper was to perform a systematic review of injuries sustained by judo athletes.

\section{METHODS}

Literature search: A comprehensive search of the literature was performed electronically in different databases from their inception up to June 2013. The use of the Medical Subject Headings (MeSH) terms 'martial arts' and 'judo' and 'injuries' produced 40 publications from PubMed/Medline. Twelve of these were deemed relevant to the present work because of the useful information on judo injuries. Further searches using the same terms were carried out in the ISI Web of Knowledge, Scopus and The Cochrane Library, and injury reports from recent Olympic Games have been investigated. Of 61 publications, 13 were found to be relevant for the present review. The exclusion criteria adopted for all search strategies were cases or case series reports dealing with less than eight participants or Japanese language. Furthermore, two book chapters on judo comprising injury data have been included. Finally, to complement the present review, selected references cited in the aforementioned literature have been considered in the case of limited information on specific topics.

\section{Definitions of injury}

According to $\mathrm{MeSH}$, injuries are primarily defined as damage inflicted on the body as the direct or 
indirect result of an external force, with or without disruption of structural continuity. However, as a result of different designs of the reviewed literature, including prospective ${ }^{8} 91214$ as well as retrospective studies, ${ }^{13} 1516$ it was not possible to adopt a standardised definition, neither of injury, nor of the severity grade of injuries. During the Summer Olympic Games (SOG), an injury was defined when an athlete received medical attention for a newly incurred injury or reinjury after full participation following the previous injury, including in-competition as well as training injuries during the SOG. ${ }^{8} 9$ Similarly, Green et $a l^{12}$ defined an injury as a situation in which the judoka either requested medical treatment or was unable to continue a contest. On the other hand, James and Pieter ${ }^{14}$ indicated an injury as any circumstance for which assistance was sought from the medical personnel, including time-loss injuries, which kept the athlete from completing the actual bout and/or subsequent bouts and from participating in judo for a minimum of 1 day thereafter. Regarding retrospective studies, an injury was defined as any physical complaint sustained by a competitor irrespective of the need for medical attention or time-loss from activities, $^{13}{ }^{15}$ or which caused an exclusion from sports-related activities for at least 4 days. ${ }^{16}$

\section{Presentation of data}

Data extraction and presentation focused on the frequency, types, location and causes of injuries. Judo injuries were expressed as absolute as well as relative frequencies. The number of injured athletes divided by the number of athletes at risk is used as an estimator of the average injury risk. ${ }^{17}$ The incidence rate is the number of injuries divided by the number of athlete-exposures, for example, the number of fights, and is based on the epidemiological concept of person-time at risk. $^{12} 141718$ It has to be noted that comparisons can only be made between data using the same denominator.

\section{RESULTS}

\section{Frequency of injuries}

Online supplementary table S1 presents data on the injury risk and incidence rate in judo practice reported in the available literature.

The most recent injury data from the 2008 SOG in Beijing and 2012 in London revealed an average injury risk of 11.2$12.3 \%$ for the more than 380 participating judo athletes per SOG. ${ }^{8} 9$ Also, James and Pieter ${ }^{14}$ and Green et $a l^{12}$ found that $13-14 \%$ of the athletes studied sustained an injury while other studies showed clearly higher injury risks of 23-29\%. ${ }^{13} 19$ The highest value was identified by Souza et $a l^{11}$ with an incidence rate of 1.18 injuries/athlete-year. The differences might be due to the different skill levels of participating athletes, involved age groups, study designs as well as injury definitions.

With regard to the potential sex differences, the reported findings were inconsistent. ${ }^{12} 1419$ Some studies found no sex difference $^{12}$ while other studies showed a higher injury risk among men ${ }^{14}$ and women, ${ }^{19}$ respectively. Again, these differences might be due in part to different skill levels and age groups.

The importance of age as a risk factor is also uncertain, especially as it may interact with experience as a causal factor. ${ }^{3}$

Recent studies on elite judokas reported a higher injury risk (49-88\%) during competition compared with training. ${ }^{8} 91120$ In contrast, other authors ${ }^{15} 2122$ showed an about 70\% higher injury risk during training compared with competition, particularly in women $\left(94 \% ;^{21}\right.$ see online supplementary tables S1-S3). An unequal proportion of time spent in training and competition during the different studies could have led to the discrepancies in the results, which may even have been influenced by memory bias. $^{23}$

Frey et $a l^{24}$ reported a higher frequency of injuries during lower level competitions compared with higher level ones. Moreover, competitions with a high difference in the performance level of the contestants showed a higher frequency of injuries. $^{24}$

\section{Injury types}

The distribution of injury types seems to be strongly influenced by the study design (see online supplementary tables S2 and S3). Regardless of the study design and sex, the most frequent injuries were sprains (5.6-59.8\%), strains (7-33.8\%) and contusions (5.6-56\%; see online supplementary tables S2 and S3). The frequency of fractures demonstrated in retrospective studies based on institutional documentation (RD) ${ }^{21} 2225$ was considerably higher than in retrospective studies utilising questionnaires $(\mathrm{RQ})^{11^{26}}$ and in prospective studies. ${ }^{12} 192728$ Prospective studies recorded a higher variety in the classification of sustained injuries, but the percentage of serious injuries was lower ${ }^{19} 2728$ when compared with RD studies. ${ }^{21} 2225$

Besides a somewhat higher percentage of sprains among female judo athletes and of strains among male judo athletes, no relevant differences have been shown between sexes (see online supplementary tables S2 and S3).

In adult as well as top-class competitors, dislocations and sprains prevailed, whereas in younger as well as lower ranked judokas upper body fractures were more frequent. ${ }^{28-30}$

\section{Injury location}

Judo injuries mostly affect body extremities, especially the knee (up to $28 \%$ ), ${ }^{20}$ shoulder (up to $22 \%$ ) and hand/fingers (up to $30 \%$ ), as shown in online supplementary table S4. Depending on the definition of injury used, fingers were sometimes indicated as the most common injury locations during competition $^{12} 13$ as a consequence of grip fighting, ${ }^{13} 3132$ which indeed has the biggest time share during the fight. ${ }^{33}$ However, these injuries were usually classified as 'soft'. ${ }^{13}$ On the other hand, RQ studies identified the knee and shoulder as the most frequent injury locations as a consequence of throwing or being thrown. 111520

No difference in the localisation of injuries has been reported between male and female judokas. ${ }^{15} 22$

In children (12.6 \pm 2.8 years, range $5-17$ years), the shoulder/ upper arm (19\%), foot/ankle (16\%) and elbow/lower arm (15\%) were the most common injury locations. ${ }^{25}$

\section{Injury causes}

Data on injury causes in judo are presented in online supplementary table S5. Nearly $85 \%$ of judo injuries occurred during standing fight compared with ground fight, probably because more time is spent in standing fight, where athletes must grip their opponent before attacking. ${ }^{12} 13$ Indeed, as already presented, grip fighting constitutes a cause of injury to hands and fingers. ${ }^{13} 3132$ Being thrown seems to be the most frequent situation leading to judo injuries, comprising about 70\% (range 42$90 \%$ ) of cases, ${ }^{3} 25$ including also a few severe and catastrophic injuries $^{34} 35$ (see online supplementary table S5). Additionally, it was indicated that the lack in falling skills is also associated with injuries, ${ }^{36}$ including acute as well as chronic ones. ${ }^{3} 34$

No age-related or sex-related causes could be found in the literature. ${ }^{19}$ Indeed, a biomechanical analysis of judo techniques revealed that both men and women use similar techniques in 
contemporary Olympic tournaments. ${ }^{37}$ However, women seem to be more exposed during ground fight, ${ }^{14}$ where their injuries are frequently derived from arm lock techniques. ${ }^{14}$ Moreover, the loss of balance in women was the main cause of injuries when performing throws and break falls. ${ }^{21}$ Among men, these causes were predominant in younger age classes, that is, from 10 to 19 years (about 48\%), whereas being pressed against the mat by the opponent or a fall on the opponent occurred most often from the age of 20 years (33\%). ${ }^{21} 28$

Furthermore, Seoi Nage techniques, that is, the throws with 'lever applied with variable arm', 37 were supposed to be highrisk techniques for shoulder injuries being thrown, ${ }^{15}$ and for knee injuries performing the throw ${ }^{26}$ in all age categories and for both genders. ${ }^{19}$ However, results on the frequency of knee injuries while performing this technique are discordant. ${ }^{38}$ Moreover, there is a high risk of repeated injuries after the first lesion sustained during these shoulder throws, mostly caused by the too quick resumption of physical activity after the sustained trauma. ${ }^{26}$ Also, improper technique is supposed to be involved in the injury mechanism of delivering throws. ${ }^{39}$

\section{Mechanisms of the most frequent judo injuries}

The mechanisms of judo injuries are varied. A study by the French Judo Federation ${ }^{24}$ on 150067 fights showed that injuries affected the shoulder in $28.7 \%$ of cases, the elbow in $13.5 \%$, the knee in $12.2 \%$ and the ankle and fingers less frequently.

Glenohumeral dislocations are mostly caused by the resistance to fall from the defender who, in an attempt to not fall on the back (which would mean losing the fight), finally falls with an outstretched arm. ${ }^{40}{ }^{41} \mathrm{~A}$ fall on the top of the shoulder, instead, causes acromioclavicular or sternoclavicular disjunctions ${ }^{42}$ or rather clavicle fractures mainly among children and adolescents with immature bones. ${ }^{42} 43$

Elbow dislocations are mainly caused by a wrong defence, ${ }^{14}{ }^{44}$ when the defender leans with a bent arm on the mat. ${ }^{45}$ The armlocks can lead to medial collateral ligament (MCL) lesions. ${ }^{46}$

Considering sport practice, a judo trauma seems to be the injury cause of anterior cruciate ligament (ACL) rupture in $5.6 \%$ of the cases. ${ }^{7}$ Knee sprains, which mainly affect the MCL and ACL in the judo population, ${ }^{47}$ are often caused by leg techniques, for example, O Soto Gari. ${ }^{38} 48$ Also, having a different grip style from the opponent seems to be a risk factor for ACL injuries. ${ }^{38}$ Lesions of the collateral ligament vary according to the violence of the trauma. ${ }^{38}$ Isolated MCL injuries can be caused by a trauma in the flexion and valgus. ${ }^{49}$

Ankle injuries are usually sprains of the collateral lateral ligament occurring during torsion in varus. ${ }^{50} \mathrm{~A}$ violent external rotation can lead to a rupture of the anterior inferior tibiofibular ligament. ${ }^{51}$

The finger injuries are commonly dislocations or sprains of the interphalangeal joints, mostly due to a wrong grip with the finger/s blocked in the swell of the judogi (kimono). ${ }^{48}$

Choking techniques are based on a push on the larynx or carotid associated with a support behind the neck. ${ }^{52}$ A loss of consciousness may occur if the defender does not give up the fight in time.

\section{Severity of injuries and time loss}

Online supplementary table S6 shows that judo is not at high risk for sustaining time-loss injuries during the Olympic Games: an average injury risk of $6.4-8.9 \%$ has been shown during the last two SOGs. ${ }^{8} 9$
As highlighted in online supplementary table S7, mean absence from training and competition ranged from 1 to 7 days (sustained by $5.7 \%$ of competitors) after injuries sustained during the $\mathrm{SOG}^{9}$ to $21-29$ days after injuries sustained during lower level competitions. ${ }^{12}$

No differences concerning the frequency and/or duration of time loss after judo injuries could be found comparing competitors of different proficiency levels ${ }^{12}$ or sex. ${ }^{8} 912$

Retrospective studies reported $65-70 \%$ of time-loss injuries happening during training. ${ }^{15} 22$ The highest risk for time loss was found at the age between 20 and 24 years, probably because it is the most intensive training and competition period. ${ }^{22}$ In adult athletes, the knee was the most common location of time-loss injuries 91215202226 followed by the shoul$\mathrm{der}^{22}$ while in children $(12.6 \pm 2.8$ years $)$ there were more shoulder/upper arm, lower leg/foot/ankle and elbow/lower arm injuries. ${ }^{25}$

\section{Severe injuries}

The main locations of catastrophic injuries in judo are the brain and the cervical spine. ${ }^{34} 35$

Kamitani et $a l^{35}$ reported being thrown as the leading injury mechanism of severe head injuries (70\%) among judo practitioners, ${ }^{35}$ who were mainly younger than 20 years $(90 \%)$ and practicing judo for less than 3 years $(60 \%) .{ }^{35}$ The authors assumed lack of falling skills as the prominent cause for severe head injuries among inexperienced judokas. ${ }^{35}$

Generally, choking in judo induces only subclinical electroencephalographic perturbations, ${ }^{53}$ but could also lead to brain damage when the 'choker' maintains the pressure on the opponent's neck, with blood flow interruption lasting a sufficient time to be harmful to the central nervous system ${ }^{54}$; in the worst case, this could lead to death. ${ }^{34}$

In Japan, 26 judokas sustained a spinal cord injury during a 3 -year period ${ }^{55}$ and 19 a neck injury in 8 years. ${ }^{35}$ Sixty-three per cent of neck injuries occurred while performing a throwing technique, for example, Uchi Mata. ${ }^{35}$

\section{Chronic injuries}

Practicing judo can cause chronic injuries, especially those affecting the finger joints, the lower back and the ears. ${ }^{32} 5657$

Repetitive injuries to the finger joints due to extensive judo training are a risk factor for the development of osteoarthritis. ${ }^{32}$

Okada et $a l^{56}$ reported a prevalence of non-specific lower back pain (nsLBP) and lumbar radiological abnormalities (LRA) in elite Japanese judokas of $35.4 \%$ and $81.7 \%$, respectively. The prevalence of LRA in the lightweight categories was lower than among middleweights and heavyweights and there was a higher coprevalence of LRA and nsLBP in the middleweight categories. $^{56}$

Rodriguez et $a l^{58}$ found competitive active judokas having no chronic brain damage induced by the repetitive application of judo-specific throwing and choking techniques.

The so-called judo ear, or cauliflower deformation of the ear, which derives from a traumatic auricular haematoma caused by repeated direct traumas, hitting and/or rubbing to the external ear, ${ }^{596}$ is typical in judo and some other combat sports. ${ }^{57}$

\section{Judo injuries in children and juveniles}

The most common types of injuries in young judo athletes (5-17 years old) are contusions/abrasions (25-45\%), fractures (28$31 \%)$ and sprains/strains (19-24\%). ${ }^{25} 61$ Studies on competition injuries in young age classes found similar results but for fractures. $^{19} 62$ Probably most of the reported fractures occurred 
during the learning process of throwing and falling techniques, or during practice with heavier opponents. ${ }^{15}$ Although there is no consensus in the literature on age classes at risk, ${ }^{3}$ Frey et $a l^{24}$ found higher competition injury rates in judo athletes between 16 and 20 years of age, in which the judo athletes are very combative but whose technical and tactical skills are still immature.

\section{DISCUSSION}

During the Olympic Games in 2008 and 2012, an average injury risk of about $11-12 \%$ has been observed. Sprains, strains and contusions, usually of the knee, shoulder and fingers, were the most frequently reported injuries, whereas being thrown was the most common injury mechanism.

The injury risk during the two most recent SOG of about 11$12 \%$ is well in accordance with the average injury risk of $11 \%$ for all sport disciplines together in the 2012 SOG. $^{8}{ }^{9}$ In comparison, taekwondo had the highest injury risk with $39.1 \%$ during the London Games while in archery, canoe slalom and sprint, track cycling, rowing, shooting and equestrian sport less than $5 \%$ of athletes were injured. ${ }^{9}$

Compared with other Olympic combat sports, judo time-loss injury risk of $6-9 \%$ during the last two SOGs was clearly lower than in taekwondo (16-18\%) but slightly higher than in boxing (4-8\%) and wrestling (5-6\%), respectively. ${ }^{8} 9$

It is notable that diverging results were influenced by different study designs and definitions of injury: retrospective studies showed a higher percentage of injuries as they usually cover entire careers of judokas until the moment of the questionnaire, while prospective studies are generally oriented to shorter and well-defined periods.

\section{Influence of nutrition, hydration and weight cycling on judo injuries}

Although nutrition, hydration and weight cycling are considered important injury risk factors in combat sports, ${ }^{63-67}$ specific research on judo is still very scarce. ${ }^{67} \mathrm{~A}$ higher frequency of injuries and impairment of muscular function have been found in weight cycling judokas and among those undergoing rapid weight reduction before a competition compared with control groups of judo athletes. ${ }^{12} 6869$ Moreover, even if bone injuries were not higher in judokas displaying disordered eating behaviours, ${ }^{70}$ the higher risk of bone injuries due to changes in bone metabolism has been referred as a consequence of weight cycling in judo. ${ }^{71}{ }^{72}$ Nevertheless, the strength requirements and technical characteristics of judo practice may also be preventive factors for bone loss and bone-related injuries. ${ }^{73}$ Furthermore, it has been reported ${ }^{74}$ that the fluid restriction practiced by many judo athletes when involved in weight loss processes, ${ }^{75}$ in conjunction with intense judo training in hot environments, resulted in serious dehydration, which might provoke heat-related injuries. Death has rarely been reported as a consequence of dehydration in judo ${ }^{67}$ and wrestling. ${ }^{76}$

Despite the described risks, most judo athletes reduce their weight a short time before competition. ${ }^{75} 7778$ The methods used include fluid restriction, sauna or plastic clothing, diuretics or laxatives, or food restriction, among others. ${ }^{78} 79$ In line with Artioli et $a l,{ }^{66}$ it can be concluded that athletes, especially prepubescent ones, must avoid harmful weight loss procedures in terms of sports injury prevention and further actions, including specific programmes, must be promoted to dissuade judo athletes from these methods. Judo should follow the example of wrestling, where these programmes started to be implemented since the late 1990 s. $^{76}$ To create a daily energy deficit of 500$1000 \mathrm{kcal}$, a long-term soft diet and aerobic exercise have been recommended for losing weight without harming the athletes' health. ${ }^{80}$ More importantly, strict regulations would be the best way to avoid dangerous weight loss practices in judo, as has been the case for wrestling. ${ }^{66} 80$

\section{Psychological factors associated with judo injuries}

The research results of recent years reinforce the assumption that psychological factors are involved in the development of sports injuries. ${ }^{81-83}$ The perceived similarity and control seem to directly contribute to the perceived risk of injury. ${ }^{82}$ The perceived similarity of an athlete with the 'typical judoka who gets injured while practicing judo' might especially be a pathway to the time and effort spent in analysing the risk information critically, which might lead to developing preventive actions. ${ }^{82}$ Some studies in non-judokas refer to the three central elements of selfdetermination theory (autonomy, competence and relatedness) fostering intrinsic motivation and seem to be related to the return to sport following injury. ${ }^{84}$ Accordingly, there is preliminary evidence that positive psychological responses (motivation, confidence and low fear) are associated with a higher rate of returning to sport. $^{84}$

Future research on judokas should aim at reducing injuries by testing cognitive behavioural strategies, which have shown efficacy in other sport settings, by performing randomised clinical trials based on the extended theoretical framework of stress-injury models. ${ }^{81} 85$

\section{Injury prevention measures during training and competition}

The knowledge on judo injuries is indispensable for the development of preventive measurements.

Considering the relatively high frequency of upper body injuries being thrown in judo, to improve falling skills, ${ }^{25} 353686$ by means of good and frequent break fall training, avoiding to fall on the top of the shoulder or on the palm of the hand, ${ }^{87}$ should be the highest priority of judo coaches, especially when teaching beginners and young practitioners. Also, balance training as well as testing the training effects in young judokas might be useful in the evaluation and reduction of the risk of falls. ${ }^{88}$ As throwing could also be dangerous, throwing techniques should likewise be carefully and correctly apprehended from the very beginning. ${ }^{25} 353686$ Furthermore, it is important to have good physical preparation, especially by stimulating long-term resistance training practice, ${ }^{2} 48990$ mainly focusing on women's upper body strength, as a high level of strength and flexibility showed a significantly lower injury rate. ${ }^{91-94}$

A specific programme for ACL injury prevention with proprioceptive exercises and knowledge of the risk situations, in addition to a higher emphasis on bilateral grips during training, would be useful in reducing knee injuries. Changing the rules, including the prohibition of direct attacks with the hand on the pants, seems to reduce knee sprains. ${ }^{6}$ However, this should be assessed more extensively in future studies. Yamamoto et al ${ }^{95}$ showed elastic taping to have a preventive function on ankle instability. Additionally, the quality of the mat is also important: even if collisions, that is, head impacts, would be attenuated on relatively soft mats, the feet would penetrate into the mat, which could lead to knee ligament injuries. ${ }^{48}$ A soft protective headgear could be an option to decrease head injuries as well as 'cauliflower ear'. ${ }^{14} 57$ The frequency of finger injuries has to be assessed in future follow-up studies to determine if the recent changes in the international judo rules from 2013 concerning grip fight will have a positive influence. 


\section{Educational programmes}

Injury prevention can be improved by providing education for athletes, coaches, referees and tournament directors 2425619697 and establishing minimum standards of qualification and experience for trainers and referees. ${ }^{35} 619697$ They should also be instructed in the mechanisms, prevention and treatment of injuries. ${ }^{96}$ Furthermore, judokas need to be aware of the importance of entering competition fully recovered from past injuries. ${ }^{16}{ }^{26}$ In addition, one decisive criterion of the ability to compete could be the scores in the Special Judo Fitness Test (SJFT). ${ }^{98}$ During the rehabilitation process, judo coaches can compare individual progress in SJFT, aiming at the achievement of the scores athletes had before sustaining the injury. ${ }^{26}$ Moreover, athletes should be encouraged to give up on time in case of armlocks and choking techniques $^{14}$ as well as to interrupt the fight in case of moderate injuries. On the other hand, the role of the referee is also relevant, especially during armlocks and choking techniques, stopping the fight if the athlete is unable to give up. ${ }^{6}$

It is also necessary to reflect on the re-evaluation of the current competition rules. ${ }^{3} 99$ Specific rules should keep on developing for the young categories having safe practice as a main concern. Hard or uncontrolled throwing, holding, joint locking or choking techniques and dangerous falling techniques, for example, trying to avoid falling on the back, can cause injuries and even serious damage, ${ }^{15} 193562$ and should be strictly penalised for the preservation of young athletes' health. Moreover, children and juveniles or inexperienced judokas should be prevented from entering competition prematurely. ${ }^{96} 99$ Competitions for athletes of different levels of experience, as those organised by the French Judo Federation, should be encouraged.

A correct pedagogical approach should not be forgotten. Studies on sports traumas indicate that the injury risk is lower if goals of achievement are proposed to players: sport exercise for health, physical maintenance or pleasure causes $9 \%$ fewer accidents than practice driven by aspiration of good performance, success in competition or desire of taking risks. ${ }^{100}$ Therefore, a reorientation of performance goals to goals of achievement, especially for young judo practitioners, would probably reduce the injury risk.

\section{CONCLUSIONS}

The present review provides the latest knowledge on the frequency and characteristics of injuries in judo. Comprehensive knowledge about the risk of injury during sport activity and related risk factors represents an essential basis to develop effective strategies for injury prevention. Thus, the introduction of an ongoing injury surveillance system in judo is of the utmost importance.

\section{What are the new findings?}

- The present review provides the latest knowledge on the frequency and characteristics of injuries in judo.

- Injuries of extremities, especially of the knee, shoulder and fingers, are the most frequently affected body parts in judo practitioners.

- Sprains, strains and contusions are the most common injury types.

- Being thrown during standing fight is the predominant situation where injuries occur.
- Introduction of an ongoing injury surveillance system in judo.

- Awareness about the risk situations, with particular emphasis on the correct learning of judo techniques, bilateral grips during training and avoiding weight cycling.

- Preventive measures will focus on improving protective equipment, which could be useful especially during training.

\section{Author affiliations}

${ }^{1}$ Department of Sport Science, University of Innsbruck, Innsbruck, Austria

${ }^{2}$ Faculty of Sport and Physical Education, University of Nis, Nis, Serbia

${ }^{3}$ Combat Sports Unit, Department of Theory of Sport and Kinesiology, Institute of Sport, University School of Physical Education, Cracow, Poland

${ }^{4}$ Sports Training and Physical Performance Research Group, Federal University of Pelotas, Pelotas, Brazil

${ }^{5}$ Martial Arts and Combat Sports Research Group, Sport Department, School of Physical Education and Sport, University of São Paulo, São Paulo, Brazil

${ }^{6}$ Department of Physical and Sport Education, University of León, León, Spain

${ }^{7}$ Unit of Orthopaedic and Sport Surgery, CHU La Pitié-Salpétrière, Paris, France

${ }^{8}$ Nollet Institute of Locomotor System, Paris, France

${ }^{9}$ Faculty of Sport Science, University of Montpellier, Montpellier, France

${ }^{10}$ National Track \& Field Centre, Sports Injury Clinic, Sports Medicine Clinic of S.E.G.

A.S., Thessaloniki, Greece

${ }^{11}$ Thessaloniki SPORTS Medicine Clinic, Thessaloniki, Greece

Contributors EP contributed to the conception and design, acquisition, analyses and interpretation of the data, drafting, accurate and critical revision, and final approval of the version of the paper to be submitted. She is the guarantor. GR, NS, SS, FBDV, CG-G and RR contributed to the analyses and interpretation of the data, drafting, critical revision and approval of the final version of the paper. MW, VM, PK and $\mathrm{MC}$ contributed to the acquisition of the data, drafting and approval of the final version of the paper. MK contributed to the analyses and interpretation of the data, accurate and critical revision of the paper as well as approval of the final version. BM contributed to the acquisition of the data, accurate and critical revision of the paper as well as approval of the final version. NM contributed to the conception as well as revision and approval of the final version of the draft paper. MB contributed to the conception and design, accurate and critical revision as well as final approval of the version of the paper to be submitted.

Competing interests None.

Provenance and peer review Not commissioned; externally peer reviewed.

\section{REFERENCES}

1 Pocecco E, Faulhaber M, Franchini E, et al. Aerobic power in child, cadet and senior judo athletes. Biol Sport 2012;29:217-22.

2 Pocecco $E$, Gatterer $H$, Ruedl $G$, et al. Specific exercise testing in judo athletes Arch Budo 2012;8:133-9.

3 Harmer PA. Judo. In: Caine DJ, Harmer PA, Schiff MA, eds. Epidemiology of injury in Olympic Sports. Oxford, UK: Wiley-Backwell, 2010:161-75.

4 Pocecco $E$, Burtscher $M$. Sex-differences in response to arm and leg ergometry in juvenile judo athletes. Arch Budo 2013;9:181-7.

5 Gutiérrez García C, Pérez Gutiérrez M, Svinth J. Judo. In: Green T, Svinth J. eds Martial arts of the world. An encyclopedia of history and innovation. California: ABC-CLIO, Santa Barbara, 2010;1:127-32.

6 IJF. International Judo Federation. http://www.ijf.org/ (accessed 30 Jun 2013).

7 Kobayashi H, Kanamura T, Koshida S, et al. Mechanisms of the anterior cruciate ligament injury in sports activities: a twenty-year clinical research of 1,700 athletes. J Sports Sci Med 2010;9:669-75.

8 Junge $A$, Engebretsen $L$, Mountjoy $M L$, et al. Sports injuries during the Summer Olympic Games 2008. Am J Sports Med 2009;37:2165-72.

9 Engebretsen L, Soligard T, Steffen K, et al. Sports injuries and illnesses during the London Summer Olympic Games 2012. Br J Sports Med 2013;47:407-14.

10 Steffen K, Soligard T, Engebretsen L. Health protection of the Olympic athlete. $\mathrm{Br}$ J Sports Med 2012;46:466-70.

11 Souza M, Monteiro H, Del Vecchio F, et al. Referring to judo's sports injuries in São Paulo State Championship. Sci Sports 2006;21:280-4. 
12 Green CM, Petrou MJ, Fogarty-Hover ML, et al. Injuries among judokas during competition. Scand J Med Sci Sports 2007;17:205-10.

13 Pierantozzi E, Muroni R. Judo high level competitions injuries. Medit J Musc Surv 2009;17:26-9.

14 James G, Pieter W. Injury rates in adult elite judoka. Biol Sport 2003;20:25-32.

15 Barsottini $D$, Guimarães $A E$, de Morais PR. Relação entre técnicas e lesões em praticantes de judô. Rev Bras Med Esporte 2006;12:56-60.

16 Witkowski K, Maslinski J, Stefaniak T, et al. Causes of injuries in young female judokas. Arch Budo 2012:8:109-16.

17 Knowles SB, Marshall SW, Guskiewicz KM. Issues in estimating risks and rates in sports injury research. J Ath/ Train 2006;41:207-15.

18 Barrault D, Achou B, Sorel R. Accidents et incidents survenus au cours des compétitions de judo. Symbian 1983;15:144-52.

19 Pieter W, De Crée C. Competition injuries in young and adult judo athletes. Abstract book of the Second Annual Congress of the European College of Sport Science. Copenhagen, Denmark: Springer, 1997;709-10.

20 Cynarski WJ, Kudlacz M. Injuries in martial arts and combat sports-a comparative study. Arch Budo 2008;4:91-7.

21 Sterkowicz S. Analiza wypadków u kobiet i mężczyzn uprawiających judo w latach 1977-1980. Sport Wyczynowy 1983;4:33-40.

22 Kujala UM, Taimela S, Antti-Poika I, et al. Acute injuries in soccer, ice hockey, volleyball, basketball, judo, and karate: analysis of national registry data. BMJ 1995:311:1456-8.

23 Del Vecchio FB, Gonçalves A. Descriptive epidemiology of sports injuries. Rev Bras Med 2012;69:323-7.

24 Frey $A$, Rousseau D, Vesselle $B$, et al. Neuf saisons de surveillance médicale de compétitions de judo. J Traumatol Sport 2004;21:100-9.

25 Yard EE, Knox CL, Smith GA, et al. Pediatric martial arts injuries presenting to emergency departments, United States 1990-2003. J Sci Med Sport 2007;10:219-26.

26 Rukasz W, Sterkowicz S, Kłys A. Causes and injuries during ippon-seoi-nage throw. Arch Budo 2011;7:17-19.

27 Sterkowicz S. Wypadkowość na VI Akademickich Mistrzostwach Świata w Judo Wrocław 1980. Sport Wyczynowy 1981;10:48-52.

28 Sterkowicz S. Wypadki w judo w świetle wieloczynnikowej analizy epidemiologicznej.Accidents in judo in multifactorial epidemiologic analysis. Rocz Nauk Akad Wychowania Fiz Krakowie 1987;22:199-243.

29 Sterkowicz S. Poziom sportowy a częstość i charakter wypadków u osób uprawiających judo. Wychowania Fizyczne i Sport 1985;3:60-75.

30 Sterkowicz S, Rukasz W. Typowe urazowe uszkodzenia ciała i ogólne wskazania w rehabilitacji ruchowej judoków. Medycyna Sportowa 1996;64/65:12-17.

31 Frey A, Müller W. Heberden arthroses in judo athletes. Schweiz Med Wochenschr 1984:114:40-7.

32 Strasser $\mathrm{P}$, Hauser $\mathrm{M}$, Häuselmann $\mathrm{HJ}$, et al. Traumatic finger polyarthrosis in judo athletes: a follow-up study. Z Rheumatol 1997;56:342-50.

33 Miarka B, Panissa V, Julio UF, et al. A comparison of time-motion performance between age groups in judo matches. J Sports Sci 2012;30:899-905.

34 Uchida R. Deaths during the judo classes and activities conducted under the supervision of schools in Japan; from 1983 to 2009. All cases listed and analyzed. Aichi University of Education. http://judojiko.net/eng/wp-content/uploads/2011/01/ en_judo_data110110.pdf (accessed 31 Jun 2013).

35 Kamitani T, Nimura Y, Nagahiro $S$, et al. Catastrophic head and neck injuries in judo players in Japan from 2003 to 2010. Am J Sports Med 2013;41: 1915-21.

36 White C, Rollitt P. Judo. In: Kordi R, Maffulli N, Wroble R, et al., eds. Combat sports medicine. London: Springer, 2009:247-62.

37 Sterkowicz S, Sacripanti A, Sterkowicz-Przybycień K. Techniques frequently used during London Olympic judo tournaments: a biomechanical approach. Arch Budo 2013;9:51-8.

38 Koshida S, Deguchi T, Miyashita K, et al. The common mechanisms of anterior cruciate ligament injuries in judo: a retrospective analysis. $\mathrm{Br}$ I Sports Med 2010;44:856-61.

39 Koiwai E. Major accidents and injuries in judo. Arizona Med 1965;22:957-62.

40 Crichton J, Jones DR, Funk L. Mechanisms of traumatic shoulder injury in elite rugby players. Br J Sports Med 2012;46:538-42.

41 Longo UG, Huijsmans PE, Maffulli N, et al. Video analysis of the mechanisms of shoulder dislocation in four elite rugby players. J Orthop Sci 2011;16:389-97.

42 Chillemi C, Franceschini V, Dei Giudici L, et al. Epidemiology of isolated acromioclavicular joint dislocation. Emerg Med Int 2013;2013:171609.

43 Hudson VJ. Evaluation, diagnosis, and treatment of shoulder injuries in athletes. Clin Sports Med 2010;29:19-32.

44 McLatchie GR, Miller JH, Morris EW. Combined force injury of the elbow jointthe mechanism clarified. Br J Sports Med 1979;13:176-9.

45 Linscheid RL, Wheeler DK. Elbow dislocations. JAMA 1965;194:1171-6.

46 Scoggin JF, Brusovanik G, Pi M, et al. Assessment of injuries sustained in mixed martial arts competition. Am J Orthop 2010:39:247-51.

47 Majewski M, Habelt S, Steinbruck K. Epidemiology of athletic knee injuries: a 10-year study. Knee 2006;13:184-8.
48 Barrault D, Brondani JC, Rousseau D. Médecine du Judo. Paris, France: Masson, 1991:113-223.

49 Laprade RF, Wijdicks CA. The management of injuries to the medial side of the knee. J Orthop Sports Phys Ther 2012;42:221-33.

50 den Bekerom MPJ, Kerkhoffs GM, McCollum GA, et al. Management of acute lateral ankle ligament injury in the athlete. Knee Surg Sports Traumatol Arthrosc 2013;21:1390-5.

51 Mak MF, Gartner L, Pearce J. Management of syndesmosis injuries in the elite athlete. Foot Ankle Clin 2013;18:195-214.

52 Egoumenides M. Traumatologie des Sports de Combat. Paris, France: Sauramps Médical, 1989:26-35.

53 Rau R, Raschka C, Brunner K, et al. Spectral analysis of electroencephalography changes after choking in judo (juji-jime). Med Sci Sports Exerc 1998;30:1356-62.

54 Wedlake L, Rowe M. La estrangulación carotídea: dormir, ¿tal vez morir? Rev Artes Marciales Asiáticas 2009;4:50-69.

55 Katoh S, Shingu H, Ikata T, et al. Sports-related spinal cord injury in Japan (from the nationwide spinal cord injury registry between 1990 and 1992). Spinal Cord 1996:34:416-21.

56 Okada T, Nakazato K, Iwai K, et al. Body mass, nonspecific low back pain, and anatomical changes in the lumbar spine in judo athletes. J Orthop Sports Phys Ther 2007;37:688-93.

57 Catanese AJ. The medical care of the judoka: a guide for athletes, coaches and referees to common medical problems in judo. Tucson, AZ: Wheatmark, 2012:36-7.

58 Rodriguez G, Vitali P, Nobili F. Long term effects of boxing \& judo-choking on brain. Ital J Neurol Sci 1998;19:367-72.

59 Fujiwara M, Suzuki A, Nagata T, et al. Cauliflower ear dissection. J Plast Reconstr Aesthet Surg 2011;64:e279-82.

60 Spencer DC. Narratives of despair and loss: pain, injury and masculinity in the sport of mixed martial arts. Qual Res Sport Exerc Health 2012:4:117-37.

61 Salanne $\mathrm{S}$, Zelmat $\mathrm{B}$, Rekhroukh $\mathrm{H}$, et al. Traumatismes secondaires à la pratique du judo chez l'enfant. Arch Pédiatrie 2010;17:211-18.

62 James $\mathrm{G}$, Pieter W. Competition injuries in young judo athletes. Proceedings of the First International Judo Federation Judo Conference, 4-5 October, Birmingham, UK, 1999.

63 Boisseau N. Consequences of sport-imposed weight restriction in childhood. Ann Nestlé 2006:64:77-84.

64 Agel J, Ransone J, Dick R, et al. Descriptive epidemiology of collegiate men's wrestling injuries: National Collegiate Athletic Association Injury Surveillance System, 1988-1989 through 2003-2004. J Athl Train 2007;42:303-10.

65 Kordi R, Maffulli N, Wroble R, et al. eds. Combat sports medicine. London: Springer, 2009:21-40.

66 Artioli GG, Franchini E, Nicastro $H$, et al. The need of a weight management control program in judo: a proposal based on the successful case of wrestling J Int Soc Sports Nutr 2010;4:7-15.

67 Franchini E, Brito CJ, Artioli GG. Weight loss in combat sports: physiological, psychological and performance effects. J Int Soc Sports Nutr 2012;9:52.

68 Prouteau S, Ducher G, Serbescu C, et al. Gender differences in response to weight cycling in elite judoists. Bio/ Sport 2007;24:91-104.

69 Umeda T, Nakaji S, Shimoyama T, et al. Adverse effects of energy restriction on myogenic enzymes in judoists. J Sports Sci 2004;22:329-38.

70 Rouveix M, Bouget M, Pannafieux C, et al. Eating attitudes, body esteem, perfectionism and anxiety of judo athletes and nonathletes. Int J Sports Med 2007;28:340-5.

71 De Crée C. Hypoestrogenemia and rhabdomyolysis (myoglobinuria) in the female judoist: a new worrying phenomenon? J Clin Endocrinol Metab 1995:80:3639-45

72 De Crée C. Acute weight cycling versus long-term judo practice in male and female judoists. Med Sci Sports Exerc 2007;39:208.

73 Prouteau S, Pelle A, Collomp K, et al. Bone density in elite judoists and effects of weight cycling on bone metabolic balance. Med Sci Sports Exerc 2006:38:694-700.

74 Rivera-Brown AM, De Felix-Davila RA. Hydration status in adolescent judo athletes before and after training in the heat. Int J Sports Physiol Perform 2012;7:39-46.

75 Artioli GG, Gualano B, Franchini E, et al. Prevalence, magnitude, and methods of rapid weight loss among judo competitors. Med Sci Sports Exerc 2010:42:436-42.

76 Centers for Disease Control and Prevention. Hyperthermia and dehydration-related deaths associated with intentional rapid weight loss in three collegiate wrestlersNorth Carolina, Wisconsin, and Michigan, November-December 1997. MMWR Morb Mortal Wkly Rep 1998:47:105-8.

77 Fabrini SP, Brito CJ, Mendes EL, et al. Práticas de redução de massa corporal em judocas nos períodos pré-competitivos. Rev Bras Educação Fís Esporte 2010:24:165-77.

78 Brito CJ, Castro Martins Roas AF, Souza Brito IS, et al. Methods of body-mass reduction by combat sport athletes. Int J Sport Nutr Exerc Metab 2012;22:89-97.

79 Langan-Evans C, Close GL, Morton JP. Making weight in combat sports. Strength Cond J 2011:33:25-39.

80 Horswill CA. Making weight in combat sports. In: Kordi R, Maffulli N, Wroble R, Wallace WA, eds. Combat sports medicine. London: Springer, 2009:21-40. 
81 Andersen MB, Williams JM. A model of stress and athletic injury: prediction and prevention. J Sport Exerc Psychol 1988;10:294-306.

82 Deroche T, Stephan Y, Woodman T, et al. Psychological mediators of the sport injury — perceived risk relationship. Risk Anal 2012;32:113-21.

83 Vago P, Casola F, Lovecchio N, et al. Anxiety and injuries in soccer players. Br J Sport Med 2013;47:e3.

84 Ardern CL, Taylor NF, Feller JA, et al. A systematic review of the psychological factors associated with returning to sport following injury. $\mathrm{Br}$ I Sport Med 2012;47:1120-6.

85 Perna FM, Antoni MH, Baum A, et al. Cognitive behavioral stress management effects on injury and illness among competitive athletes: a randomized clinical trial. Ann Behav Med 2003;25:66-73.

86 Fetto JF. Judo and karate. In: Fu FH, Stone DA, eds. Sports injuries, mechanisms, prevention, treatment. 2nd edn. Philadelphia: Lippincott Williams \& Wilkins, 1994:545-57.

87 Kalina RM, Barczynski B, Jagiello W, et al. Teaching of safe falling as most effective element of personal injury prevention in people regardless of gender, age and type of body build - the use of advanced information technologies to monitor the effects of education. Arch Budo 2008:4:82-90.

88 Kalina RM, Jagiełło W, Barczyński BJ. The method to evaluate body balance disturbation tolerance skills - validation procedure of the 'Rotational Test'. Arch Budo 2013;9:59-80.

89 Nadler SF, Malanga GA, Deprince $M$, et al. The relationship between lower extremity injury, low back pain and hip muscle strength in male and female collegiate athletes. Clin I Sports Med 2000;10:89-97.
90 Franchini E, Del Vecchio FB, Matsushigue KA, et al. Physiological profiles of elite judo athletes. Sports Med 2011;41:147-66.

91 Henry T. Resistance training for judo: functional strength training concepts and principles. Strength Cond I 2011;33:40-9.

92 Kort HD, Hendriks ERHA. A comparison of selected isokinetic trunk strength parameters of elite male judo competitors and cyclists. I Orthop Sports Phys Ther 1992:16:92-6

93 Ruivo R, Pezarat-Coreia P, Carita Al. Elbow and shoulder muscles strength profile in judo athletes. Isokinetics Exerc Sci 2012;20:41-5.

94 Pierantozzi E, Muroni R, Lubisco A. Evaluation of the morphology and physiology of judokas' upper body intended to prevent injuries. Medit J Musc Surv 2010;18:1-5.

95 Yamamoto T, Kigawa A, Xu T. Effectiveness of functional ankle taping for judo athletes: a comparison between judo bandaging and taping. $\mathrm{Br} J$ Sports Med 1993;27:110-12.

96 Pieter W. Martial arts injuries. Med Sport Sci 2005;48:59-73.

97 McPherson M, Pickett W. Characteristics of martial art injuries in a defined Canadian population: a descriptive epidemiological study. BMC Public Health 2010:10:1471-2458.

98 Franchini E, del Vecchio F, Sterkowicz S. A special judo fitness test classificatory table. Arch Budo 2009:5:127-9.

99 Zetaruk M. Children in combat sports. In: Kordi R, Maffulli N, Wroble R, Wallace WA. eds Combat sports medicine. London: Springer, 2009:151-72.

100 Ministère des Sports, France, stat-info 12-05, 2012:3. http://www.sports.gouv.fr/IMG/ archives/pdf/STAT-Info_no12-05_de_decembre_2012.pdf (accessed 31 Jun 2013). 